\title{
Environmental characteristics associated with alcohol intoxication among patrons in Brazilian nightclubs
}

\author{
CLAUDIA CARLINI ${ }^{1}$, SOLANGE ANDREONI ${ }^{1}$, SILVIA S. MARTINS ${ }^{2}$, MIGUEL BENJAMIN $^{1}$, \\ ADRIANA SANUDO ${ }^{1} \&$ ZILA M. SANCHEZ ${ }^{1}$
}

\author{
${ }^{1}$ Department of Preventive Medicine, Universidade Federal de São Paulo, São Paulo, Brazil, and ${ }^{2}$ Department of \\ Epidemiology, Columbia University, New York, USA
}

\begin{abstract}
Introduction. Few studies have investigated the association between environmental factors and patrons' binge drinking in nightclubs, and such studies are rare in developing countries. Objective. To identify environmental factors associated with binge drinking among patrons in nightclubs in São Paulo, Brazil, using a mixed-methods design. Method. The study used a two-stage cluster sampling survey design. Two levels of data were collected: observational data and portal survey data. Individual-level data were collected by a portal survey of 2422 subjects at the entrance and 1822 subjects at the exit of 31 nightclubs. Weighted multilevel analysis was used to investigate the association between patrons' binge drinking (as measured by breath alcohol concentration $\geq 0.38 \mathrm{mg} \mathrm{L^{-1 }}$ ) at nightclub exit, with environmental-level variables collected through observation and controlled for individual-level data. Results. Pre-drinking was the variable most strongly associated with binge drinking BrAC levels when exiting the venue [adjusted odds ratio (aOR) $=5.98,95 \%$ confidence interval (CI) [4.37, 8.17], $\mathrm{P}<0.001)$. The environmental variables significantly associated with binge drinking were 'all you can drink' service $(a O R=2.44,95 \% C I[1.03,0.79] ; \mathrm{P}=0.043)$, two or more dance floors $(a O R=1.92,95 \% C I[1.16,3.18] ; \mathrm{P}=0.011)$, and higher sound levels ( $a O R=1.04$ per each decibel increased, $95 \%$ CI [1.01, 1.08]; $\mathrm{P}=0.048)$. Data triangulation showed an association between lower alcohol intoxication and ketamine use in three LGBT nightclubs. Discussion. Pre-drinking showed that individual-level characteristics could be more important in binge drinking than the venues' environmental characteristics. Previous studies failed to include pre-drinking in environmental analysis. Conclusion. Environmental control interventions, isolated from individual-level approaches, may have limited efficacy in the prevention of alcohol abuse in nightclubs. [Carlini C, Andreoni S, Martins SS, Benjamin MM, Sanudo A, Sanchez ZM. Environmental characteristics associated with alcohol intoxication among patrons in Brazilian nightclubs. Drug Alcohol Rev 2014;33: 358-66]
\end{abstract}

Key words: nightclubs, binge drinking, alcohol intoxication, drinking environments, Brazil.

\section{Introduction}

Research has shown that environmental characteristics in nightclubs, such as sound level, alcoholic beverage discounts, a large amount of people in the venue and a high temperature may increase the consumption of alcoholic beverages by patrons $[1,2]$. The same is true for individual-level variables, such as gender, youth and intention to drink, which are correlated with increased alcohol consumption in these venues [3].
Nightclubs and bars are places of choice for the practice of binge drinking (which is defined as drinking so much that within approximately 2 hours, blood alcohol concentration levels reach $0.08 \%$ ) [4] among young adults and adolescents [5-7]. However, it is important to note that the term binge drinking can represent diverse measures in different settings [8].

Because binge drinking is a dangerous pattern of alcohol consumption and is associated with physical aggression, risky sexual behaviour, sexual violence

Claudia Carlini BSSc, PhD candidate, Reseacher Assistant, Solange Andreoni MSc, PhD, Professor of Biostatistics, Silvia S. Martins MD, PhD, Professor of Epidemiology, Miguel Benjamin, MD candidate, Adriana Sanudo MSc, Statistical Researcher, Zila M. Sanchez MSc, PhD, Professor of Epidemiology. Correspondence to Dr Zila M. Sanchez, Universidade Federal de São Paulo, Rua Botucatu, 740, 4th floor, São Paulo, SP, 04023-900, Brazil. Tel: +55 11 55764997; E-mail: zila.sanchez@unifesp.br

Received 21 December 2013; accepted 17 April 2014. 
[9-11] and mortality [12] at these venues, it is considered to be a public health concern.

Understanding the environmental and individuallevel characteristics that can facilitate alcoholic intoxication in the nightlife economy is important in informing licensing policy and harm-reduction initiatives to reduce intoxication-related harm in nightclubs and bars [13].

Although there has been an increase in the scientific literature on this topic over the last decade, all extant studies were conducted in countries in Europe, North America and Oceania, leaving a large gap in the knowledge of this behaviour in less wealthy and more unequal countries $[2,14]$.

Binge drinking has recently emerged as a public health issue in Brazil [15], and until now, no epidemiological study of alcohol consumption in nightclubs has ever been published in that country, where the legal drinking age is 18 and current policies allow drinking in public areas, including streets, beaches and parks. The unregulated sale of alcohol is common, and most existing regulations are poorly enforced [16].

Thus, the objective of this study is to identify environmental-level factors that may be associated with binge drinking among patrons in nightclubs in São Paulo, Brazil, in order to provide important data that may support alcohol control policies in nightclubs in a developing country.

\section{Methods}

A mixed-methods design was used to investigate the alcohol use behaviour of patrons at nightclubs and environmental factors that might promote alcohol consumption in these establishments.

\section{Sampling of nightclubs and patrons}

This study was a two-stage cluster sampling portal survey, defined as a form of intercept sampling specifically designed to capture at-risk individuals at the entrance to and exit from locales of increased alcohol and other drug risks [17]. The nightclub selection (first stage) consisted of a systematic sample of 40 nightclubs, with probability of inclusion proportional to their maximum capacity. The patron selection (second stage) was a systematic sample of every third person in the entrance lines of the selected nightclubs [17] (see Supporting Information Appendix S1 for details).

In this survey, nightclubs were defined as leisure venues that sell alcoholic beverages, have one or more dance floors, and offer individual control of patron entry and exit through the payment of an entrance fee.

The nightclub frame list was created by an active search of magazines and guides specialising in leisure activities and a search of the first ten pages returned from a Google search using the following key word: 'São Paulo bars, nightclubs and discos' (in Portuguese). The final frame list consisted of 150 nightclubs meeting the inclusion criteria, from which 40 nightclubs and potential replacements were drawn (see Supporting Information Appendix S1 for details) [18].

The inclusion criteria for patrons to participate in the study were the following: intention to enter the nightclub and being 18 years or older. If the patron refused to participate, data on age and gender were registered, and the next person in line was approached.

A sample size of 1600 patrons was calculated so that the prevalence of alcohol intoxication could be estimated to within 5 percentage points (absolute precision) of the true value set to $50 \%$ (maximum variance) with $95 \%$ confidence, two stages of cluster sampling and a design effect of 2 [19]. Taking into account a refusal rate of $30 \%$ and a maximum follow-up loss of $40 \%$ from patron entrance to patron exit, grounded in previous studies by Clapp et al. [18], it was determined that 2912 patrons should be initially approached.

\section{Data collection and instruments}

Two levels of data were collected in the study: environmental data (characteristics of the nightclub) and individual-level data (patrons of the nightclub).

Nightclub instruments. Observational research was conducted inside the nightclubs that agreed to participate in the study. Each nightclub was observed once for an average of $8.5 \mathrm{~h}$-i.e. from the time the club opened to the time it closed-by two trained researchers. Two instruments were used: (i) a structured questionnaire based on the KAReN (Kit for Assessment of Recreational Nightlife) venue questionnaire [20] and Safer Bars [21] (details in Supporting Information Appendix S1); and (ii) a field diary filled out during and immediately after the observational research, with four thematic axes: drinking behaviour, violence, sexual behaviour and illicit drug use in the nightclubs. The observational procedure follows the guidelines of Patton and Bernard [22,23]. Humidity (\%) and temperature $\left({ }^{\circ} \mathrm{C}\right)$ were measured by a professional thermohygrometer (INSTRUTHERM HT, model 270; INSTRUTHERM, São Paulo, Brazil) and sound level $(\mathrm{dB}$ ) by a sound level meter (INSTRUTHERM DEC, model 490).

Patron instruments. The patrons who agreed to participate took entrance and exit survey interviews and a breathalyser (Dräger Alcotest 7410 Plus RS, Dräger, Lübeck, Germany) test after each interview. The patrons received a bracelet with a unique code to 
identify them at the exit. Seven field researchers used Samsung Galaxy tablets to collect data from the interviews and send those data to a central database in real time. The entrance questionnaire investigated sociodemographic variables, pre-drinking (a positive result on the breathalyser test with breath alcohol concentration (BrAC) $\geq 0.01 \mathrm{mg} \mathrm{L}^{-1}$ ), drinking patterns, drug use and risk behaviours in nightclubs in the year prior to the survey. The exit questionnaire asked about alcohol consumption, drug use and risk behaviours patrons engaged in on that specific night inside the venue.

\section{Variables}

The outcome variable for the statistical analysis was breath alcohol concentration levels equivalent to those of binge drinking (defined here as 'binge drinking alcohol concentration') at the time of exit $(0=$ no, $1=$ yes). Patrons' binge drinking (alternately, alcohol intoxication) was defined as a $\mathrm{BrAC} \geq 0.38 \mathrm{mg} \mathrm{L}^{-1}$, which corresponds to a blood alcohol concentration of $0.08 \%$ (the mean concentration of a binge drinking episode) $[4,24]$. The aspects of the nightclubs that were evaluated as explanatory variables are presented in detail in Supporting Information Appendix S1.

\section{Statistical analyses and weighting}

We computed weights for nightclubs, patrons within each nightclub and patrons overall. Post-stratification adjustments were made using the information about the sex of all customers present at each nightclub (a total of 23100 patrons were present in the 31 nightclubs on the days of data collection, $59 \%$ men and $41 \%$ women). Non-participation adjustment rates for the nightclub weights were also calculated.

Descriptive and inferential statistics on the sampled patrons and nightclubs were computed using survey weight estimates. We also investigated the patterns of non-response for patrons under this approach.

Multilevel logistic models with random intercepts were used to evaluate the association of binge drinking $\mathrm{BrAC}$ at nightclub exit with patrons' individual characteristics (level 1) and nightclub characteristics (level 2). The maximisation of a pseudo-likelihood through an adaptive quadrature approach was used for estimation because it can accommodate the probability weights of each level of sampling [25]. It is necessary to scale the sampling weights at each level, and this step was performed here, as is recommended for informative sampling methods used to select units at both levels of sampling [25,26]. In multilevel analysis, the weights should be given for each level of analysis (details about weighting are presented in Supporting Information Appendix S1).
First, a null multilevel model with explanatory variables was fitted. Second, models for each characteristic and the bivariate association of binge drinking BrAC at exit were fitted. Then, models that examined the association of the outcome and all predictor variables of each block, controlling for pre-drinking, were fitted. Variables with $P<0.20$ in the models by block were used to build a final model. Explanatory variables with $P<0.05$ composed the final model. Coefficients are presented in terms of odds ratio (OR) and adjusted odds ratio (aOR) to facilitate interpretation (see Supporting Information Appendix S1 for details).

An additional model including a variable (yes/no) for venues exhibiting ketamine use at the nightclub level ('ketamine venue') was investigated under the same modelling approach and using the same variables presented in Table 1, replacing illicit drug use with ketamine use.

The models were estimated using the GLLAMM package for Stata 2012 software [27].

\section{Content analysis of field diaries}

Each night of observation in the field diary was identified by a numeric code and was analysed using the content analysis technique described in Bardin's theoretical framework. Field notes were sorted into major themes (i.e. portions in agreement with each thematic axis) and grouped into reports [28]. At this stage, the computer software NVivo 10 was used [29].

The themes identified were analysed to provide meaning, taking into consideration the emic approach [28]. This step, defined as categorisation, was performed by three researchers working together to ensure consistency and coherence in the analysis [22].

\section{Ethics}

The Research Ethics Committee of the Universidade Federal de São Paulo (protocol 21477) approved this study. No interview was conducted with patrons showing signs of severe intoxication, following the guidelines for screening described in Perham et al. [30].

\section{Results}

\section{Sample characteristics}

Of the 40 original nightclubs selected for sampling, 31 (including replacements) agreed to participate, resulting in an acceptance rate of $66 \%$.

A total of 3063 patrons of the 31 nightclubs were recruited to answer questions in an entrance and exit portal survey. An entrance acceptance rate of $80 \%$ generated a sample of 2422 completed entrance interviews 
Table 1. Environmental characteristics of the 31 randomly selected São Paulo nightclubs

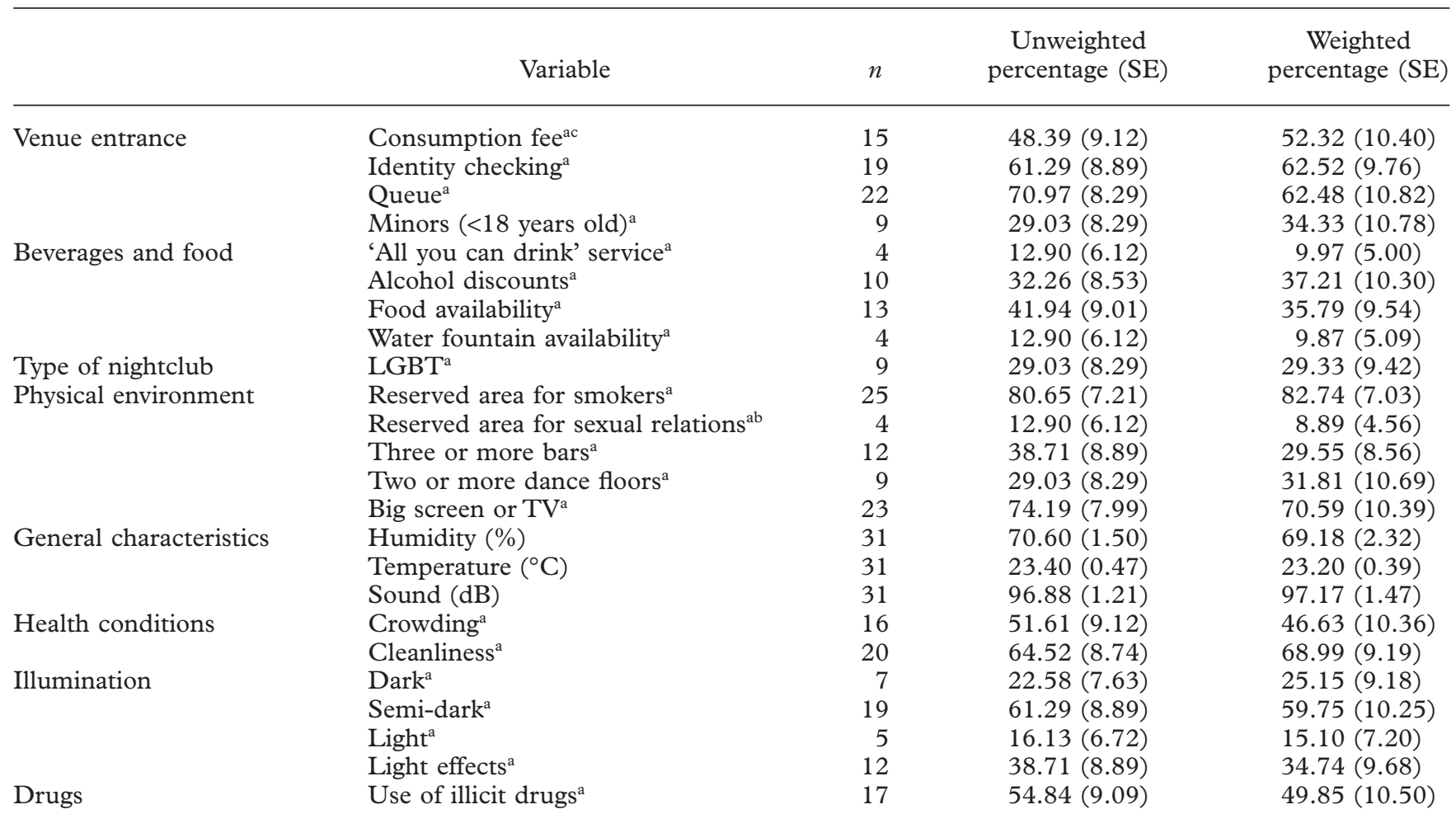

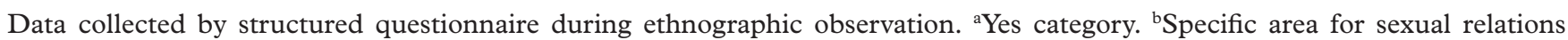
(some clubs host a darkened room that patrons can use for casual sex). 'Patrons pay a more expensive entrance fee (usually double the price of the regular fee) and then consume the total amount of money spent at the entrance in beverages. Once the total amount is paid, any money not consumed through beverages will not be refunded.

and a follow-up rate of $76 \%$, representing 1832 complete exit interviews (1822 with breathalyser result).

Non-responses in the exit interview stemmed from different reasons: refusal to participate $(n=12,2.1 \%)$, inability to answer due to severe intoxication $(n=67$, $11.3 \%)$ and loss to follow-up $(n=511,86.6 \%)$. There were no statistically significant differences in the sex $\left(\chi^{2}=0.02, P=0.889\right)$ or pre-drinking $\left(\chi^{2}=0.88\right.$, $P=0.355)$ distributions or the mean age $(t=0.11$, $P=0.917)$ among the participants who were interviewed at both time points (entrance and exit) and those who were interviewed at entrance but not at exit.

Table 1 presents the environmental characteristics of the nightclubs that were hypothesised to be associated with patrons' drinking behaviour. Table 2 presents the demographic characteristics and pre-drinking status of patrons re-interviewed at exit.

Pre-drinking was observed in $34.33 \%(\mathrm{SE}=3.85)$ of patrons, binge drinking alcohol concentration at entry in $9.35 \%(\mathrm{SE}=1.35)$ of patrons, and binge drinking alcohol concentration at exit in $31.11 \%(\mathrm{SE}=3.06)$ of patrons.

\section{Multilevel analysis}

The final multilevel model showed that pre-drinking had the strongest significant association with alcohol intoxication at exit $[\mathrm{aOR}=5.98,95 \%$ confidence interval (CI) [4.37, 8.17], $P<0.001]$. 'All you can drink' service (patrons pay a fixed value at the entrance allowing them completely unrestricted alcohol consumption inside the establishment) had the next strongest association with alcohol intoxication $(\mathrm{aOR}=2.44,95 \% \mathrm{CI}$ $[1.03,5.79], P=0.043)$. Dance floors and sound levels were also statistically significantly associated with exit intoxication (Table 3).

The preliminary verification of a multilevel model without explanatory variables for alcohol intoxication at exit indicated a between-cluster variability of 0.96 $(\mathrm{SE}=0.44)$; the final multilevel model reduced this to $0.47(\mathrm{SE}=0.16)$.

The field diary content analysis (presented below) raised a hypothesis concerning the inverse association of ketamine use with alcohol intoxication using multilevel analysis (data not shown in tables). Ketamine use 
Table 2. Sociodemographic characteristics of patrons interviewed at nightclub exit $(\mathrm{n}=1822)$

\begin{tabular}{|c|c|c|c|c|}
\hline Sex & Male & 1111 & $60.98(1.14)$ & $60.71(5.89)$ \\
\hline & Female & 711 & $39.02(1.14)$ & $39.29(5.89)$ \\
\hline Age & $18-24$ years & 897 & $49.23(1.17)$ & $59.47(4.57)$ \\
\hline Pre-drinking & Yes & 683 & $37.49(1.13)$ & $34.33(3.85)$ \\
\hline Binge drinking BrAC at entry & Yes & 186 & $10.21(0.71)$ & $9.35(1.61)$ \\
\hline Binge drinking $\mathrm{BrAC}$ at exit & Yes & 569 & $31.22(1.09)$ & $31.11(3.06)$ \\
\hline
\end{tabular}

Data from the entrance interview. BrAC, breath alcohol concentration.

Table 3. Multilevel models for the associations between environmental characteristics and binge drinking BrAC for patrons at exit ( $\mathrm{n}=1822$ interviewees in 31 nightclubs)

\begin{tabular}{|c|c|c|c|c|c|c|c|c|}
\hline \multirow[b]{2}{*}{ Block } & \multirow[b]{2}{*}{ Variable } & \multicolumn{2}{|c|}{ Bivariate } & \multicolumn{2}{|c|}{ Block } & \multicolumn{3}{|c|}{ Final model } \\
\hline & & OR & $P$ & $\mathrm{aOR}$ & $P$ & $\mathrm{aOR}$ & $95 \% \mathrm{CI}$ & $P$ \\
\hline \multicolumn{9}{|l|}{ Patrons } \\
\hline Patrons' behaviour & Pre-drinking ${ }^{\mathrm{a}}$ & 5.80 & $<0.001$ & & & 5.98 & {$[4.37,8.17]$} & $<0.001$ \\
\hline \multirow{2}{*}{ Demographics } & Male & 1.24 & 0.370 & 0.91 & 0.698 & & - & \\
\hline & Age $18-24$ & 1.13 & 0.419 & 1.24 & 0.224 & & - & \\
\hline \multicolumn{9}{|l|}{ Nightclubs } \\
\hline \multirow[t]{4}{*}{ Venue entrance } & Consumption $\mathrm{fe}^{\mathrm{ad}}$ & 2.28 & 0.051 & 1.70 & 0.184 & & - & \\
\hline & Identity checking ${ }^{\mathrm{a}}$ & 1.01 & 0.978 & 0.90 & 0.807 & & - & \\
\hline & Queue $^{\mathrm{a}}$ & 1.53 & 0.477 & 1.22 & 0.699 & & - & \\
\hline & Minors $(<18 \text { years.old })^{a}$ & 1.66 & 0.184 & 1.39 & 0.398 & & - & \\
\hline \multirow{4}{*}{ Beverages and food } & 'All you can drink' servicea & 2.65 & 0.013 & 3.19 & 0.005 & 2.44 & {$[1.03,5.79]$} & 0.043 \\
\hline & Alcohol discounts ${ }^{\mathrm{a}}$ & 0.52 & 0.224 & 0.73 & 0.439 & & - & \\
\hline & Food availability & 0.47 & 0.146 & 0.58 & 0.175 & & - & \\
\hline & Water fountain availability & 1.36 & 0.581 & 1.39 & 0.501 & & - & \\
\hline Type of nightclub & LGBT $^{a}$ & 1.20 & 0.649 & 0.83 & 0.626 & & - & \\
\hline \multirow[t]{5}{*}{ Physical environment } & Reserved area for smokers ${ }^{a}$ & 1.66 & 0.152 & 1.08 & 0.851 & & - & \\
\hline & Reserved area for sexual relations $\mathrm{s}^{\mathrm{ac}}$ & 1.27 & 0.749 & 0.97 & 0.975 & & - & \\
\hline & Three or more bars ${ }^{a}$ & 0.86 & 0.757 & 1.13 & 0.781 & & - & \\
\hline & Two or more dance floors ${ }^{a}$ & 2.39 & 0.013 & 2.71 & 0.002 & 1.92 & {$[1.16,3.18]$} & 0.011 \\
\hline & Big screen or $\mathrm{TV}^{\mathrm{a}}$ & 0.50 & 0.059 & 0.49 & 0.051 & 0.50 & {$[0.28,0.90]$} & 0.011 \\
\hline \multirow{3}{*}{$\begin{array}{l}\text { Atmospheric } \\
\text { characteristics }\end{array}$} & Humidity (\%) & 0.99 & 0.421 & 0.98 & 0.322 & & - & \\
\hline & Temperature $\left({ }^{\circ} \mathrm{C}\right)$ & 1.00 & 0.981 & 0.95 & 0.579 & & - & \\
\hline & Sound $(\mathrm{dB})$ & 1.05 & 0.119 & 1.06 & 0.060 & 1.04 & {$[1.01,1.08]$} & 0.048 \\
\hline \multirow[t]{2}{*}{ Health conditions } & Crowding ${ }^{a}$ & 1.14 & 0.766 & 1.17 & 0.730 & & 1.000 & \\
\hline & Cleanliness ${ }^{\mathrm{a}}$ & 0.54 & 0.096 & 0.63 & 0.229 & & - & \\
\hline \multirow{3}{*}{ Illumination ${ }^{\mathrm{b}}$} & Semi-dark ${ }^{a}$ & 0.86 & 0.619 & 1.12 & 0.813 & & - & \\
\hline & Light $^{\mathrm{a}}$ & 0.20 & 0.033 & 0.31 & 0.208 & & - & \\
\hline & Light effects ${ }^{a}$ & 1.52 & 0.292 & 0.96 & 0.949 & & - & \\
\hline Drugs & Use of illicit drugs $\mathrm{a}^{\mathrm{a}}$ & 1.80 & 0.203 & 1.39 & 0.494 & & - & \\
\hline
\end{tabular}

${ }^{a}$ Yes category. ${ }^{b}$ Reference category: dark. ${ }^{\mathrm{c}}$ Specific area for sexual relations (some clubs host a darkened room that patrons can use for casual sex). ${ }^{\mathrm{d}}$ Patrons pay a more expensive entrance fee (usually double the price of the regular fee) and then consume the total amount of money spent at the entrance in beverages. Once the total amount is paid, any money not consumed through beverages will not be refunded. aOR, adjusted odds ratio; BrAC, breath alcohol concentration; OR, odds ratio. 
was observed by researchers and declared by patrons in three LGBT venues. Using the same modelling approach, analysis supported that intoxication was less prevalent in these 'ketamine use' venues $(\mathrm{aOR}=0.37$, 95\% CI [0.23, 0.58], $P<0.001)$. For the model that includes ketamine use in the venue as a nightclub-level variable, a similar final model is obtained; however, sound level effects become marginally significant $(P=0.060)$, when ketamine use venues are added to the model.

\section{Content analysis}

Content data analysis of the field diaries supported the association between open bars and alcohol intoxication. The majority of the quotes from the thematic node 'alcohol intoxication' came from the observations conducted where 'all you can drink' service was available.

In 'all you can drink' venues, pre-drinking was less visible in the entrance line; however, people drank until the last possible moment, and it was usual to see people handling glasses at closing time.

People were drinking a lot during the night. Signs of intoxication were evident, especially after 2 am.... Many people with uncoordinated movements, bloodshot eyes, slurred speech. There were clear signs of vomiting in the bathrooms. . . . Some people tried to talk with me, but they were so drunk that I could not quite understand what they were saying ... In the exit row, a patron participating in the survey passed out when approached to answer the exit interview. (Field diary 27)

The need to include pre-drinking as a control variable of statistical analysis emerged from field observation, as in almost all venues, several patrons were drinking in the entrance line, and alcohol was being sold outside the venue by peddlers in cars or tents or through local trade, such as street bars, diners and bakeries. In some places, people came to the club already drunk, which would be a confounding factor for environmental variables.

The nightclub is located in a very busy street ... Some street bars and bakeries are on the same sidewalk as the venue. Patrons are pre-drinking in front of the nightclub, and some of them are showing signs of intoxication in the line... . Entrance of intoxicated patrons is authorised with no concerns. (Field diary 07)

Before the multilevel models were fitted, an experience in the field inspired researchers to hypothesise about the poor quality of interactions when loud music is playing, as well as its consequences for alcohol use:

The loud sound seems to decrease the degree of interaction between the patrons, and it was virtually impossible to talk there, and thus each one pays attention only to the drink and the dancing. We have to consider the hypothesis that loud sound decreases interactions and increases alcohol consumption in our analysis. (Field diary 13)

Another theme that emerged from the field diaries concerns the role of the 'agglomeration' of patrons, which seems to increase consumption of alcohol. Notes from observations indicate that extremely crowded and messy nightclubs seem to be associated with higher alcohol consumption, shown by the analysis of interaction between 'agglomeration' and 'intoxication' nodes, grouped by NVivo.

The dance floor was crowded and the sound coming out of the boxes was very loud . . . People were drinking a lot (really a lot) and ... were colliding all the time during dancing. (Field diary 12)

Considering the data triangulation [22], ketamine use was visible in three specific venues and, simultaneously, alcohol intoxication was described as less prevalent in these venues. The 'ketamine' and 'alcohol intoxication' NVivo nodes were integrated when considering low alcohol use:

I was astonished with the amount of people snorting ketamine. ... I asked a guy (he was disturbed and with red eyes) if he had enjoyed the go-go boy show. $\mathrm{He}$ replied seriously, 'What show?' ... I replied, thinking that he was joking, 'You do not remember the scene with those two guys who were up on stage?' Aggressively he replied, 'You are mistaken, there was no show today.' The alcohol use was lower than I had previously seem ... People left the venue 'high', but 'high' from other drugs, not alcoholic intoxication. (Field diary 21)

\section{Discussion}

The most relevant finding of this study is the fact that the variable most strongly associated with exiting patrons having BrACs indicating alcohol intoxication was pre-drinking behaviour (or pre-loading). Among the 24 environmental variables analysed, only four were significantly associated with alcohol intoxication after controlling for pre-drinking: number of dance floors, big screens or televisions, sound level and 'all you can drink' service. 
Pre-drinking, the main predictor in this study, has already been investigated in other countries (particularly in the USA and UK) and seems to occur when patrons aim to save money and to facilitate peer and sexual interactions [31]. It is important to note that binge drinking also occurs during the pre-drinking episodes [32], as getting drunk seems to be one of the main objectives of young people who go out for nightlife activities, independently of being inside or outside the destination venue $[5,6,33]$.

Considering the nightclub characteristics, 'all you can drink' service had the strongest significant association with patrons' intoxication at nightclub exit. These data corroborate an American study showing that in college bar districts in the United States, this discount practice is associated with a higher potential to boost patron intoxication [34].

In Brazil in 2008, a bill (number 3414/08) prohibiting parties offering 'all you can drink' service was presented to the Chamber of Deputies. The project has since stalled, although the Chamber's official web site states that this is a priority project. Moreover, in Brazil, alcohol sales are unregulated and it is legal to serve alcohol to intoxicated patrons [16], which suggests that 'all you can drink' service may be more harmful in Brazil than it is in regulated markets.

Although there is little scientific evidence to date, higher levels of sound seem to be significantly associated with patron intoxication, which was supported by qualitative and quantitative evidence in our study. An experimental study conducted in French bars showed that high levels of sound led to an increase in alcohol consumption among clients [35]. The 'arousal hypothesis' for patrons in nightclubs argues that high sound levels create a high level of excitement in patrons, which leads them to increase their alcohol consumption and reduce their waiting time between each new serving of alcohol [36].

We found a statistically significant association between the number of dance floors and binge drinking alcohol concentration at the exit. A possible explanation for this association is that higher availability of dance floors results in more people clustering around them and that crowded dance floors are associated with heavy drinking. This occurs because patrons try to alleviate their discomfort by drinking faster, as suggested in other studies [37]. Dance floors are usually the place where sound is loudest in the nightclub; thus, the arousal theory would also be an explanation. The variable 'crowding' was based on the average number of people present at the venue, independent of where people were socialising. Consistent with the finding above, crowding per se was not associated with heavy drinking. Future studies should explore alternative methods to measure 'crowding' by taking into consideration the crowd distribution.
Big screens or televisions in nightclubs were a protective factor. We assume that this is due to distinct reasons based on three different profiles of nightclubs that feature screens and televisions: (i) induced motion sickness-extreme visual stimulus from the transmission of fast, colourful, psychedelic images can generate feelings of dizziness and motion-sickness [38], reducing the desire to drink; (ii) ballroom dancing-the second group of nightclubs with big screens or televisions catered to older adults who appreciate ballroom dancing, so people seemed to be more focused on dancing than drinking; and (iii) distraction-patrons watch programs on the televisions and therefore dance less. It may be less the big screen or television itself that is the protective factor, but the type of nightclub and patrons that characterise and attend it, respectively. Studies of televisions in bars have only aggression as the outcome: televisions showing fights or aggressive programs increased violence among intoxicated patrons [39].

Several limitations are noted. The follow-up rate of $75 \%$ shows that part of the entrance sample was lost. Our hypothesis is that patrons who were drunk were more likely to leave the establishment without worrying about the exit interview. Moreover, we did not interview extremely drunk patrons. Thus, the number of intoxicated patrons may be underrated. Additionally, the variable for illicit drug use in the venue that was used in the multilevel analysis was not self-reported by participants, but observed by those conducting observational research inside the nightclub.

Another limitation is that BrACs were measured only twice during the night for each patron-some of them may have engaged in binge drinking earlier in the night, but stopped drinking a few hours before leaving the nightclub, meaning that due to blood clearance, their initial binge drinking was not detected in the exit interview. Moreover, the authors opted for an objective definition of alcohol intoxication, specifically a biological measure proposed by the National Institute on Alcohol Abuse and Alcoholism for binge drinking [4], although we know that there are patrons who become intoxicated even at lower alcohol dosages.

Because the study is a cross-sectional survey, it is not possible to infer causation from statistical association. It is also important to note that there are likely many other influences on BrAC that were not measured in this study (i.e. length of drinking session, body adiposity and race).

Despite its limitations, this study has several strengths. The most important is the inclusion of predrinking in the multilevel analysis, which has not typically been included in published studies with similar scope. The second strength is the acceptance rate of patrons $(80 \%)$ at the entrance of nightclubs in one of 
largest cities in the world [40]. Moreover, the use of a mixed-methods design, considering different approaches for data collection and data analysis, increases the validity of results.

Considering that binge drinking in nightclubs is associated with the practice of 'drinking and driving' and aggressive and risky sexual behaviour [15], methods to reduce the amount of alcohol consumed by patrons must be tested. Data support the interpretation that although some environmental variables are associated with alcohol intoxication, personal decisions can be stronger than the influence of the environment itself [41], as pre-drinking was the strongest predictor of alcohol intoxication. Thus, environmental control approaches that are isolated from individual-level approaches may not show efficacy in the prevention of alcohol intoxication in nightclubs. On the other hand, the 'all-you-can-drink' service is one environmental factor that could be addressed by public policy to limit alcohol accessibility and availability in nightclubs.

\section{Acknowledgements}

Funding for this study was provided by the São Paulo State Research Support Foundation (Fundação de Amparo a Pesquisa do Estado de São PauloFAPESP), grant numbers 2011/51658-0 for Dr Sanchez and 2012/21258-3 for PhD Candidate Carlini, and the Brazilian National Council on Research (Conselho Nacional de Desenvolvimento Científico e Tecnológico-CNPq), grant number 483385/2011-5 for Dr Sanchez. We thank all students and staff for their contributions to this research project, as well as the Preventive Medicine Department and the Brazilian Information Center on Psychotropic Drugs.

\section{References}

[1] Green J, Plant MA. Bad bars: a review of risk factors. J Subst Abuse 2007;12:157-89.

[2] Hughes K, Quigg Z, Eckley L, et al. Environmental factors in drinking venues and alcohol-related harm: the evidence base for European intervention. Addiction 2011; 106(Suppl. 1):37-46.

[3] Clapp JD, Reed MB, Min JW, et al. Blood alcohol concentrations among bar patrons: a multi-level study of drinking behavior. Drug Alcohol Depend 2009;102:41-8.

[4] National Institute of Alcohol Abuse and Alcoholism. National institute of Alcohol Abuse and Alcoholism council approves definition of binge drinking. NIAAA Newsletter 2004;3:1-4.

[5] Laranjeira R, Pinsky I, Zaleski M, Caetano R. I levantamento nacional sobre os padrões de consumo de álcool na população Brasileira [First national survey on patterns of alcohol consumption in the Brazilian population]. Brasília: Brazilian National Antidrug Secretariat (SENAD), 2007. In Portuguese.

[6] Sanchez ZM, Martins SS, Opaleye ES, Moura YG, Locatelli DP, Noto AR. Social factors associated to binge drinking: a cross-sectional survey among Brazilian students in private high schools. BMC Public Health 2011;11:201.

[7] Beets MW, Flay BR, Vuchinich S, Li KK, Acock A, Snyder FJ. Longitudinal patterns of binge drinking among first year college students with a history of tobacco use. Drug Alcohol Depend 2009;103:1-8.

[8] Courtney KE, Polich J. Binge drinking in young adults: data, definitions, and determinants. Psychol Bull 2009;135: 142-56.

[9] Bellis MA, Huges K, Calafat A, Juan M, Ramon A, Rodriguez JA. Sexual uses of alcohol and drugs and the associated health risks: a cross sectional study of young people in nine European cities. BMC Public Health 2008;8:155.

[10] Kelley-Baker T, Mumford EA, Vishnuvajjala R, Voas RB, Romano E, Johnson M. A night in Tijuana: female victimization in a high-risk environment. J Alcohol Drug Educ 2008;52:46-71.

[11] Livingston M, Chikritzhs T, Room R. Changing the density of alcohol outlets to reduce alcohol-related problems. Drug Alcohol Rev 2007;26:557-66.

[12] Leifman $\mathrm{H}$. A comparative analysis of drinking patterns in 6 EU countries in the year 2000. Contemp Drug Probl 2002;29:501-48.

[13] Miller AB, Holder HD, Voas RB. Environmental strategies for prevention of drug use and risks in clubs. J Subst Abuse 2009;14:19-38.

[14] Tutenges S. Safety problems among heavy-drinking youth at a Bulgarian nightlife resort. Int J Drug Policy 2009;20: 444-6.

[15] Silveira C, Silveira C, Silva J, Silveira L, Andrade A, Andrade L. Epidemiologia do beber pesado e beber pesado episódico no Brasil: uma revisão sistemática da literatura [Epidemiology of heavy drinking and heavy episodic drinking in Brazil: a systematic review of literature]. Rev Psiquiatr Clín 2008;35:31-8. In Portuguese.

[16] Laranjeira R. Brazil's market is unregulated. BMJ 2007; 335:735.

[17] Voas RB, Furr-Holden D, Lauer E, Bright K, Johnson MB, Miller B. Portal surveys of time-out drinking locations: a tool for studying binge drinking and AOD use. Eval Rev 2006;30:44-65.

[18] Clapp JD, Holmes MR, Reed MB, Shillington AM, Freisthler B, Lange JE. Measuring college students' alcohol consumption in natural drinking environments: field methodologies for bars and parties. Eval Rev 2007;31:46989.

[19] Lwanga SK, Lemeshow S. Sample size determination in health studies: a practical manual. Geneva: World Health Organization, 1991.

[20] Calafat A, Hughes K, Jerez MJ, et al. KAReN-Kit for Assessment of Recreational Nightlife. Available at: http:// www.irefrea.org/uploads/PDF/KAREN_Full\%20Set_EN .pdf (accessed March 2013).

[21] Graham K. Training manual for observers on the Safer Bars Study. London, Canada: Centre for Addiction and Mental Health, 2002.

[22] Patton MQ. Qualitative research and evaluation methods, 3rd edn. Thousand Oaks, CA, USA: Sage Publications, 2002 .

[23] Bernard HR. Social research methods: qualitative and quantitative approaches, 7th edn. London: Sage Publications, 2000.

[24] Haffner HT, Graw M, Dettling A, Schmitt G, Schuff A. Concentration dependency of the BAC/BrAC (blood alcohol concentration/breath alcohol concentration) 
conversion factor during the linear elimination phase. Int J Legal Med 2003;117:276-81.

[25] Rabe-Hesketh S, Skrondal A. Multilevel modeling of complex survey data. J R Statist Soc A 2006;A169:805-27.

[26] Pfeffermann D, Skinner CJ, Holmes DJ, Goldstein H, Rasbash J. Weighting for unequal selection probabilities in multilevel models. J R Statist Soc B 1998;60:23-40.

[27] Rabe-Hesketh S, Skrondal A, Pickles A. GLLAMM manual. Technical Report 160. Berkeley: Division of Biostatistics, University of California, Berkeley, 2004.

[28] Bardin L. Análise de conteúdo [Content analysis], 3rd edn. Lisbon: Edições70, 2004. In Portuguese.

[29] Gibbs GR. Qualitative data analysis: explorations with NVivo. New York: Open University Press, 2009.

[30] Perham N, Moore SC, Shepherd J, Cusens B. Identifying drunkenness in the night-time economy. Addiction $2007 ; 102: 377-80$

[31] Foster JH, Ferguson C. Alcohol 'pre-loading': a review of the literature. Alcohol Alcohol 2013;49:213-26.

[32] Dejong W, Dericco B, Schneider SK. Pre-gaming: an exploratory study of strategic drinking by college students in Pennsylvania. J Am Coll Health 2010;58:307-16.

[33] Measham F, Brain K. Binge drinking, British alcohol policy and the new culture of intoxication. Crime Media Cult 2005; $1: 262-83$.

[34] Thombs L, O'Ma R, Dodd VJ, et al. A field study of barsponsored drink specials and their associations with patron intoxication. J Stud Alcohol Drugs 2009;70:206-14.

[35] Gueguen N, Jacob C, Le Guellec H, Morineau M, Lourel $M$. Sound level of environmental music and drinking behavior: a field experiment with beer drinkers. Alcohol Clin Exp Res 2008;32:1795-8.

[36] Roballey T, McGreevy C, Rongo R, et al. The effect of music on eating behaviours. Bull Psychon Soc 1985; $23: 221-2$.
[37] Macintyre S, Homel R. Danger on the dancefloor: a study of interior design, crowding and aggression in nightclubs. In: Homel R, ed. Policing for prevention: reducing crime, public intoxication and injury, Vol. 7. Monsey, NY, USA: Criminal Justice Press, 1997:91-113.

[38] Kennedy RS, Drexler J, Kennedy RC. Research in visually induced motion sickness. Appl Ergon 2010;41:494503.

[39] Graham G, Homel R. Raising the bar: preventing aggression in and around bars, pubs and clubs. Abingdon, UK: Willan Publishing, 2011.

[40] Brazilian Institute of Geography and Statistics. Estimativas da população residente nos municípios brasileiros com data de referência em $1^{\circ}$ de Julho de 2013 [Estimates of resident populations in Brazilian municipalities with reference date of 1 July 2013]. Rio de Janeiro: Brazilian Institute of Geography and Statistics, 2013. Available at: ftp://ftp.ibge.gov.br/ Estimativas_de_Populacao/Estimativas_2013/estimativa 2013_dou.pdf (accessed March 2014). In Portuguese.

[41] Silva-Filho A, Masur J. Modulação dos efeitos do álcool por fatores individuais, situacionais e ambientais [Modulation of alcohol effects by individual, situational and environmental factors]. Ciênc Cult 1985;38:749-59. In Portuguese.

\section{Supporting Information}

Additional Supporting Information may be found in the online version of this article at the publisher's web-site:

Appendix S1. Environmental characteristics associated with alcohol intoxication among patrons in Brazilian nightclubs' 
Copyright of Drug \& Alcohol Review is the property of Wiley-Blackwell and its content may not be copied or emailed to multiple sites or posted to a listserv without the copyright holder's express written permission. However, users may print, download, or email articles for individual use. 